This is an Accepted Manuscript of the article Chifari, R., Piano, S. L., Bukkens, S. G., \& Giampietro, M. (2016). A holistic framework for the integrated assessment of urban waste management systems. Ecological Indicators, 94 (3), 25-36, available online at:

https://doi.org/10.1016/j.ecolind.2016.03.006

(C)2018. This manuscript version is made available under the CC-BY-NC-ND 4.0 license.

\title{
A Holistic Framework for the Integrated Assessment of Urban Waste Management Systems
}

\author{
Rosaria Chifari $^{\mathrm{a}}$, Samuele Lo Piano ${ }^{\mathrm{a}}$, Sandra G.F. Bukkens ${ }^{\mathrm{a}}$, and Mario Giampietro ${ }^{\mathrm{a}, \mathrm{b}^{*}}$
}

${ }^{a}$ Institute of Environmental Science and Technology, Edifici ICTA-ICP, Universitat Autònoma de Barcelona, 08193 Cerdanyola del Vallès, Spain

${ }^{\mathrm{b}}$ Catalan Institution for Research and Advanced Studies (ICREA), Passeig Lluís Companys 23, 08010 Barcelona, Spain

*Corresponding author e-mail: mario.giampietro@uab.cat

\section{Abstract}

We report on the development of a holistic framework to organize and integrate quantitative information characterizing the performance of Urban Waste Management Systems (UWMS) across dimensions and scales. The framework builds on the theory of metabolic networks and the Multi-Scale Integrated Analysis of Societal and Ecosystem Metabolism (MuSIASEM) accounting method. We perceive the UWMS as an organ of a socio-ecological system that modulates the interaction between the metabolic processes of the urban area and those of the embedding ecosystems providing inputs and local sink capacity. Building on these premises, we can define: (i) the flow of wastes produced by the urban system in quantity and quality; (ii) the mix of inputs required for the operation of the different stages of the waste management process, such as technology, labor, energy, water and material flows; (iii) the degree of openness of the system, that is, the imports and exports of urban waste flows in the different stages of its operation; (iv) the final outputs released into the local environment. The proposed framework can accommodate various indicators referring to the socio-economic performance of the UWMS (viability and desirability) and those related to environmental impact/stress (feasibility). Theoretical considerations are illustrated with preliminary data from a case study on the Metropolitan Area of Naples, Italy. 
1 Keywords: Urban waste management system; metabolic network; socio-ecological system; performance indicators; MuSIASEM; Naples.

Highlights

- We propose a meta-tool to organize and analyze data on urban waste management

- It builds on metabolic network theory and the MuSIASEM accounting method

- It accommodates ecological and economic indicators over multiple scales of analysis

- It combines with participatory processes into quantitative story-telling

- The approach is illustrated with preliminary data from a case study on Naples, Italy

\section{INTRODUCTION}

In 2014, 54 per cent of the world population was reported to live in urban areas and, according to UN projections, this percentage could reach 66 per cent by 2050 (UN, 2014). This phenomenon of massive urbanization is expected to exacerbate problems of inefficient municipal solid waste management already experienced in major cities worldwide (e.g., Bhuiyan, 2010; D’Alisa et al., 2010; Guerrero et al., 2013; Santibañez-Aguilar et al., 2013). In fact, the choice of a specific urban waste management system directly affects the metabolic pattern of a city and, as a consequence, the surrounding environment and the quality of life of its urban dwellers. Not surprisingly then urban waste management has become a crucial issue in the agenda of local and national governments both in developed and developing countries. Concomitantly, scientific research on the performance of urban waste management systems (UWMS) has seen an upsurge and various models and indicators have been proposed to support decisionmaking in municipal solid waste management (see, for example, Chang et al., 2011; Contreras et al. 2008; Hung et al., 2007; Kijak and Moy, 2004; Rigamonti , 2016; Thorneloe et al., 2007; Zaman, 2014). This has resulted in a scattered body of widely different types of qualitative and quantitative methods, individual and composite indicators, and more or less deterministic models. Morrissey and Browne (2004) reviewed the merits and shortcomings of the principal models for municipal waste management decision-making and come to the conclusion that none of the models proposed examines environmental, economic and social aspects at the same time. In line 
with their criticism, Marshall and Farahbakhsh (2013) plead for a complex systems approach, but do not make any attempt to quantification.

Indeed, an integrated quantitative assessment of UWMS performance presents a major epistemological challenge as it involves the simultaneous consideration of several dimensions (ecological, economic, technical, socio-cultural and political) and scales of analysis (spatial: household, urban zone, municipal, regional, national, and global; temporal: short-term versus long-term concerns). Moreover, the information generated by the assessment has to be relevant and useful for different stakeholders having legitimate but contrasting points of view about the performance of UWMS. Therefore, to develop a decision support system, we must first individuate relevant story-telling about the UWMS in order to provide a coherent semantic context to the quantitative assessment.

The objective of this work is to develop a holistic framework to organize and integrate quantitative information characterizing the performance of Urban Waste Management Systems (UWMS) across dimensions and scales. The proposed framework is rooted in theoretical ecology (metabolic networks) and considers the UWMS as part (organ) of a larger socio-ecological system. It provides a holistic view of the metabolic pattern of the UWMS in the form of a set of expected relations that are described in quantitative terms simultaneously across different hierarchical levels and scales. Applying the Multi-Scale Integrated Analysis of Societal and Ecosystem Metabolism (MuSIASEM) accounting (D'Alisa et al. 2012; Giampietro et al., 2013, 2014) within this framework, it is possible to characterize: (i) the quantity and quality of the flow of municipal solid waste produced by the urban system (rate and density); (ii) the mix of technical inputs (i.e., technology, labor, energy, water and materials flows) required for the operation of the different stages of the UWMS and the various economic outputs generated in this process (i.e., recycled and recovered materials, energy); (iii) the level of openness of the UWMS (i.e., inflows/outflows crossing system boundaries in the different stages of its operations); and (iv) the output of waste (gas, liquid and solid) disposed of into the local environment (within the system's boundaries). Given the characteristics of the embedding ecosystems providing sink capacity, the rate and the density of the flows released into the environment permit the calculation of an environmental load.

The proposed framework can accommodate indicators representing a wide range of domains and conceptually classify them into: 
1. Feasibility in relation to external constraints (sink capacity and the framework of laws and regulations insisting on the area under study);

2. Viability in relation to internal constraints (economic costs, technical coefficients);

3. Desirability in relation to normative values expressed by social actors.

The work presented here has been developed within the project "Material Advanced Recovery Sustainable Systems" (MARSS), funded by the European LIFE Programme and aimed at evaluating the performance of an innovative technology for processing and recycling municipal solid waste. Within this project our specific goal was to develop a methodology for the integrated assessment of the performance of UWMS and test it in the Metropolitan Area of Naples (Italy). Preliminary data from the Naples case study are used throughout this work to illustrate and validate the proposed theoretical framework.

In the next section, we briefly explain the theoretical building blocks used to develop the holistic framework of analysis. We then show how to apply this theoretical approach to UWMS and how to integrate indicators of socio-economic performance with indicators of environmental impact, using Naples as a case. Finally, we conclude with a reflection on the potential and shortcomings of the proposed holistic framework.

\section{METHODOLOGY}

We present here the theoretical concepts that underlie the proposed methodological framework for the integrated characterization of UWMS, as well as a brief description of the Naples case study.

\subsection{Metabolic networks}

The concept of metabolic network was originally developed for ecosystems in the field of theoretical ecology, but is equally well applicable to other types of complex metabolic systems. Complex systems are organized over different hierarchical levels (e.g., individual organisms, species, functional compartments, whole ecosystem) and express predictable patterns of interaction among its components and with its context (Tansley, 1935; Lindeman, 1942). As illustrated in Fig. 1, a scientific analysis of such systems therefore necessarily requires a characterization of its expected characteristics across 
1 levels and scales (Odum E.P. 1959, 1969; Odum H.T. 1971, 1983, 1996; Margalef 1968;

2 Ulanowicz 1986, 1997).

3 In graph A of Fig. 1 the ecosystem is represented as a network of interactions among 4 different functional components or nodes quantified by flows of energy (in joules) of 5 different types and forms. The taxonomy of elements, provided in graph B, allows us to 6 distinguish between interactions with the context ('energy losses' and 'source') and 7 interactions inside the network ('store', 'consumption', 'production', 'generic flow').

8 With this method of analysis we can identify the expected patterns that are expressed by 9 the metabolic network in terms of relative size of the functional components/nodes and their relative metabolic rates (determining the flows). These expected relations can then be used to develop indices referring to different aspects of the network (graphs C, D in Fig. 1) or expected relations over aggregate values (graphs E, F, G in Fig. 1).

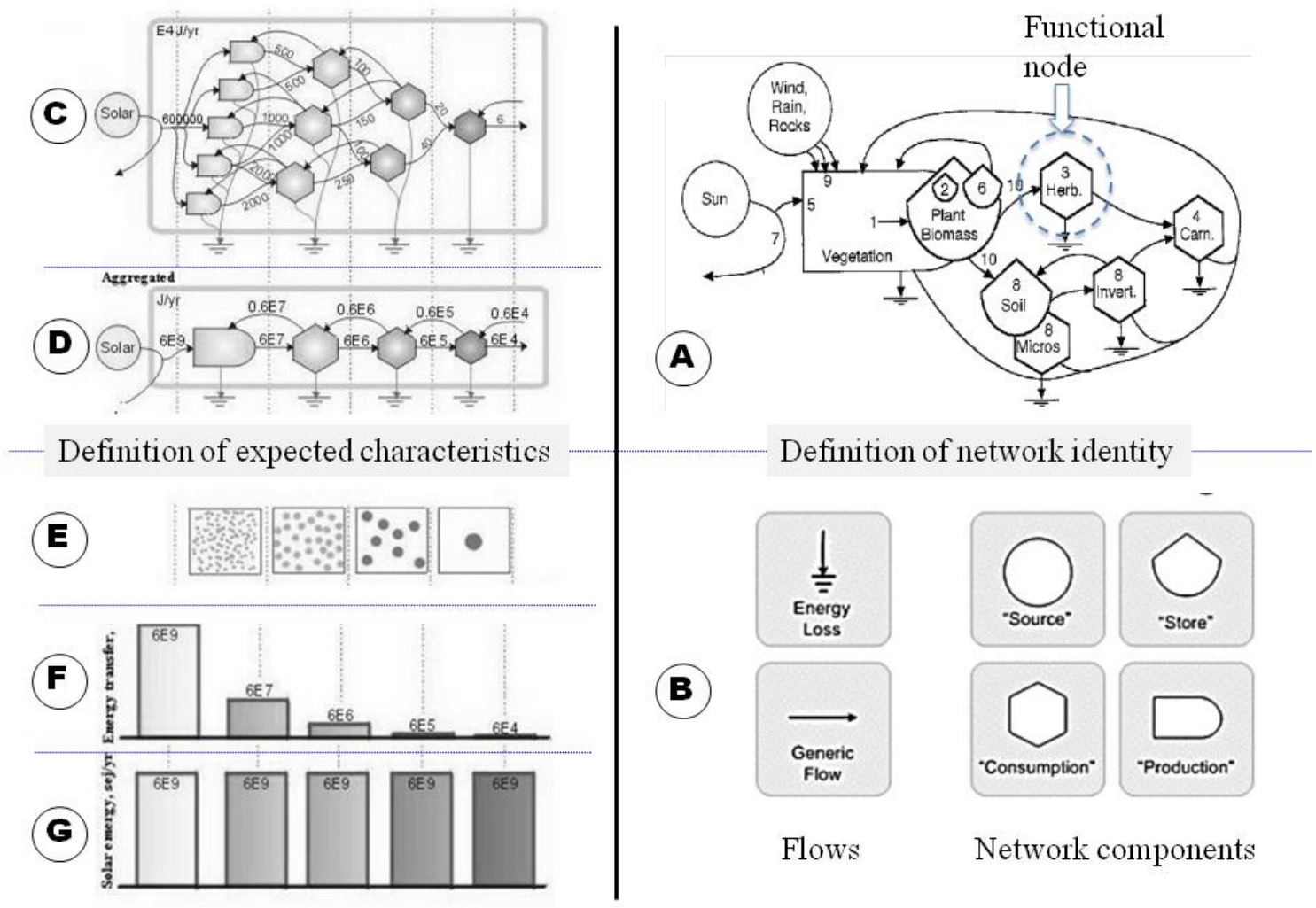

Figure 1: Quantitative relations over components and flows in an ecosystem according to H.T. and E.P. Odum. 
1 A detailed look at graph A of Fig. 1 shows that the main flow of energy feeding the ecosystem enters from outside in the form of solar energy (left side). This energy input is then transformed into plant biomass (another form of energy) by the primary producers (vegetation). The plant biomass constitutes the flow of energy input for the next node (herbivores), where it is then transformed in herbivore biomass and used by other functional components of the network. By quantifying these relations over all the components of the system, we can characterize: (i) the structure of the network; (ii) the properties of its components (what flows they use as input and what flows they generate as output); and (iii) a set of expected relations regarding the size of the network nodes and the flows they metabolize. With the latter information we can further define the required size of the structural elements that compose the functional nodes to guarantee the stability of the network in relation to the relative size of the flows.

This type of analysis thus establishes a bridge between: (i) the performance of the whole system; (ii) the characteristics of the individual elements composing the system; and (iii) the effects the system has on its context (the level of openness of the network, the inputs/outputs flowing from/to the external boundary).

Ecological network analysis has been further developed by, among others, Hannon (1973, 1985) and Fath et al. (2007) in an attempt to standardize the method of accounting (for an overview, see Fath and Patten, 1999). Important epistemological contributions were made by Rosen, Georgescu-Roegen and Koestler, and are briefly described below.

Rosen $(1958,1959)$ pointed out that a quantitative representation of a metabolic network requires two types (sources) of information referring to different scales and levels of analysis (the outside and inside perspective):

1. Information about the network, needed to specify the topological relations over the nodes and the qualitative characteristics of the different flows. This concerns the question: What is an admissible input? For instance, carnivores can metabolize herbivore and carnivore biomass but not solar radiation or plant biomass. In the same way, when dealing with an UWMS, the input entering an incinerator is different from that feeding a plant of anaerobic digestion.

2. Characteristics of the structural elements making up the nodes, observed at a lower level. Are they able to express the function expected by the rest of the network, consume the admissible input that is the output from other nodes, and generate a known output that, in turn, has to be an admissible input for the next 
4 Georgescu-Roegen (1971) proposed the flow-fund model of analysis for networks of

5 biophysical transformations and introduced the idea that metabolic networks are based on

6 flow-fund relations. The flow-fund model $^{1}$ postulates an expected relation between the

7 structural elements (the funds) making up the nodes (defined at a lower hierarchical level

8 of analysis) and the flows that are consumed (inputs) and produced (outputs). It thus

node? In the same way, technologies making up a node of a UWMS must be able to process the expected input flow of material and generate the required inputs for the successive nodes. requires a definition of: (i) the size or capacity of the (lower-level) fund elements (extensive variable), and (ii) their metabolic rate or flow throughput per unit of fund (an intensive variable). In our representation, the size of the fund is described by the conversion capacity of the plants that compose the node. It follows that flow/fund ratios are the technical coefficients describing the operation of a given plant of defined size capable of processing a certain amount of inputs and generating a certain amount of outputs.

Koestler (1968, 1978) proposed the concept of 'holon' to address the unavoidable complexity associated with metabolic networks (see also Ahl and Allen, 1996; Allen and Starr, 1982). The holon is an elusive epistemic device used by humans to perceive complex systems. It blends together the perception of functional types (e.g., the presidency of the USA being an office) and that of structural types (e.g., Mr. Barack Obama being the current incumbent). These two perceptions are associated simultaneously to the description of any given instance (see Giampietro et al., 2006). Therefore, any analysis of metabolic networks must combine the perception of functional network nodes (e.g., herbivores; incineration as a waste treatment process) with that of their structural composition (herbivorous species; different typologies of incinerators). Thus, the special ecosystem or UWMS we want to study represents an instance of an integrated set of holons or a so-called 'holarchy' (Allen and Starr, 1982).

Building further on these epistemological considerations, we can define the characteristics of a network node in two independent ways, top-down and bottom-up (see Fig. 2).

\footnotetext{
${ }^{1}$ Funds are the entities or physical structures that transform, consume, or produce flows. Funds preserve their identity over the duration of the analysis, while flows appear or disappear over the duration of the analysis.
} 

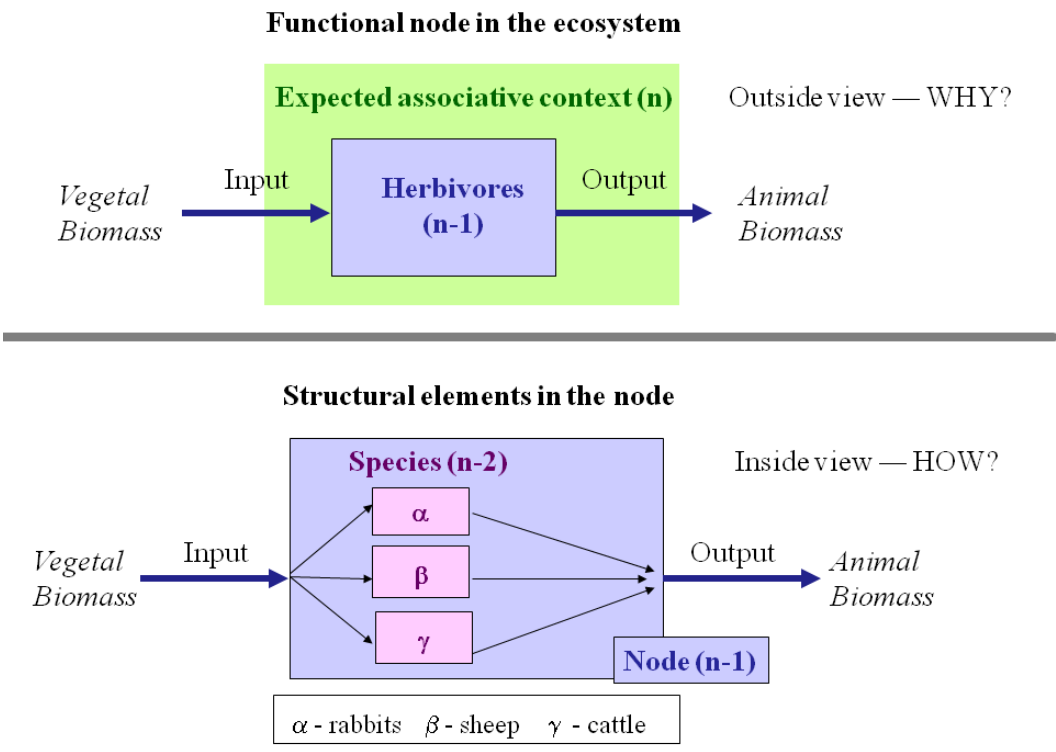

1

2 Figure 2: Top-down (upper graph) and bottom-up definition (lower graph) of the

3

metabolic characteristics of a node, across the various hierarchical levels of the system.

The metabolic network is defined as level n, the nodes as level n-1, and the structural components composing the nodes as level $n-2$.

The top-down definition or outside (external) view looks at the network niche: what the metabolic network (level $n$ ) expects, so to speak, from the node (level n-1) in order to keep the network stable and preserve its identity or essence. (The concept of network identity assumes that the taxonomy of nodes, their topological relations and the expected flow/fund ratios remain stable over the duration of the analysis). This translates into a definition (a set of expected characteristics) of: (i) what has to be processed as input and generated as output, both in quality (the nature of the admissible inputs and outputs) and quantity, by the nodes operating inside the network; and (ii) what has to be taken from or discarded into the environment by the nodes interacting with the context.

The bottom-up definition or inside (internal) view, on the other hand, studies the metabolic capacity of the node (defined at level n-1) starting from the conversion processes carried out at the local scale (level n-2). It looks at the relative composition of the structural elements making up the node, and their characteristics (metabolic rate or technical coefficients of each of these elements).

The successful operation of a metabolic network is thus based on a forced relation of congruence between the top-down definition of the nodes, providing their functional 
1 description at the interface of levels $n$ and $n-1$, and the bottom-up definition of the nodes providing their structural description (defined at the interface of levels n-1 and n-2). As shown in Fig. 2, there is no direct mapping between the top-down and bottom-up definition: the same characteristics of a given functional node can be obtained by different combinations of lower-level structural elements. This is an important observation that is usually overlooked in life cycle assessment (LCA): an output/input flow ratio referring to a given node cannot be extrapolated and applied to the analysis of other similar metabolic networks without checking how it is obtained (the mix and the characteristics of the structural elements).

Using the metabolic network approach we can thus establish a bridge among the information referring to different hierarchical levels and scales of analysis:

1. The interactions of the network as a whole with its context. This implies considering simultaneously three hierarchical levels of analysis: (i) level $n$, referring to the whole network; (ii) level $n+1$, referring to the context of the network; (iii) level $n$-1, referring to the functional components of the network (the nodes of the network);

2. The functioning of the internal parts of the network. This requires congruence of the expected characteristics of the functional nodes (determined in quantitative and qualitative terms at the interface of levels $n$ and n-1) with those of the structural elements making up these nodes (determined in quantitative and qualitative terms at the interface of levels n-1 and n-2).

In conclusion, the specific characteristics of any instance of a metabolic network can be explained by a combination of information referring to three different hierarchical levels (scales) of analysis: (i) the interaction with the context, (ii) the identity of the network; (iii) the identity of lower-level components. The purpose of the proposed framework of analysis is to bridge the quantitative information referring to these different scales and the corresponding non-equivalent, non-reducible descriptive domains (Giampietro et al. 2006). The price to pay for doing so is that we have to work with:

- impredicativity - given a quantitative representation we cannot define whether it is the top-down constraint (the characteristics of the functional element) or the bottom-up constraint (the characteristics of the structural elements) that determines the observed pattern; 
- semantic approximation - an exact mapping between functional and structural elements is impossible because they are defined across different hierarchical levels of organizations. In ecology, functional nodes are made up of species, made up of populations, made up of organisms that may express an important variability (gender, age, activity patterns) at different levels of analysis. The result of these differences may be either important or negligible depending on the goal of the analysis. In an UWMS functional nodes are made up of a combination of lowerlevel technologies (plants of different sizes and technological coefficients) that may express important variability with regard to utilization factor, ageing (deterioration), effective management.

In the rest of this paper we apply the theoretical concepts of metabolic networks to the analysis of UWMS, using the Multi-Scale Integrated Analysis of Societal and Ecosystem Metabolism (MuSIASEM) accounting scheme and drawing on preliminary data from our case study in Naples. MuSIASEM has the specific goal of integrating the outside (topdown) and the inside view (bottom-up) of the metabolic pattern of socio-ecological systems across scales, and has already been successfully applied to the analysis of the energy sector of society (Giampietro et al., 2012, 2013, 2014).

\subsection{Naples case study}

Data on the UWMS of the Metropolitan Area of Naples were collected from local statistics $\left(\mathrm{ARPAC}^{2}\right.$, ISPRA $^{3}$ ) and through interviews with various actors ${ }^{4}$ of the Neapolitan waste management scene, including members of the regional and municipal administrations; private and public companies operating in UWMS; local NGOs; activist groups; and consumer organizations. The interviews with relevant actors were carried out by the authors in September and October of 2015. The aim of the interviews was to

\footnotetext{
${ }^{2}$ Agenzia Regionale per la Protezione Ambientale Campania (Regional Agency for Environmental Protection)

${ }^{3}$ Istituto Superiore per la Protezione e la Ricerca Ambientale (Institute for Environmental Protection and Research)

${ }^{4}$ Municipal Government of Naples, Environmental Authority Department - Campania Region, ARPAC, Campania Region, ASIA (Azienda Servizi Igiene Ambientale - waste collection company); Metropolitan Area of Naples, SAPNA (Sistema Ambiente Provincia di Napoli - Environmental System Naples Province), Cittadini Campani per un Piano Alternativo dei Rifiuti (Campanian citizens for an alternative plan for waste), Hotel/Restaurant Zero Waste/ Zero Waste Campania, Lets do It! Italy
} 
1 corroborate the proposed metabolic network structure, estimate waste-flows quantities

2 and economic costs, and identify relevant social and political issues.

3

4 3. RESULTS

5

\section{$6 \quad 3.1$ Representation of the UWMS as a metabolic network}

7 In Fig. 3 we propose a simplified semantic framework to characterize the metabolism of 8 urban waste management systems (UWMS). In Fig. 3, we have:

1. The society (level $n+1)$ generating the urban solid waste throughput that is the input for the UWMS system (focal level n) (left side of Fig. 3);

2. Other socio-ecological systems (level $n+2)$ importing/exporting waste (top of Fig. $3)$.

3. The local environment (level $n+1$ ) absorbing the physical flows disposed of (right side of Fig. 3);

4. The society (level $n+1)$ re-using material generated by the UWMS (bottom of Fig. $3)$;

All the stages of municipal waste management (collection, processing, disposal and so on) taking place within the Metropolitan Area of Naples are considered as internal (e.g., the local environment falls within this border ${ }^{5}$ ). Any waste flux directed out of this area or entering the area from outside, regardless of the processing stage at which this is occurring, is considered as, respectively, exported or imported.

\footnotetext{
${ }^{5}$ In our representation, the analytical border adopted is based on an administrative/geographic criterion.
} 


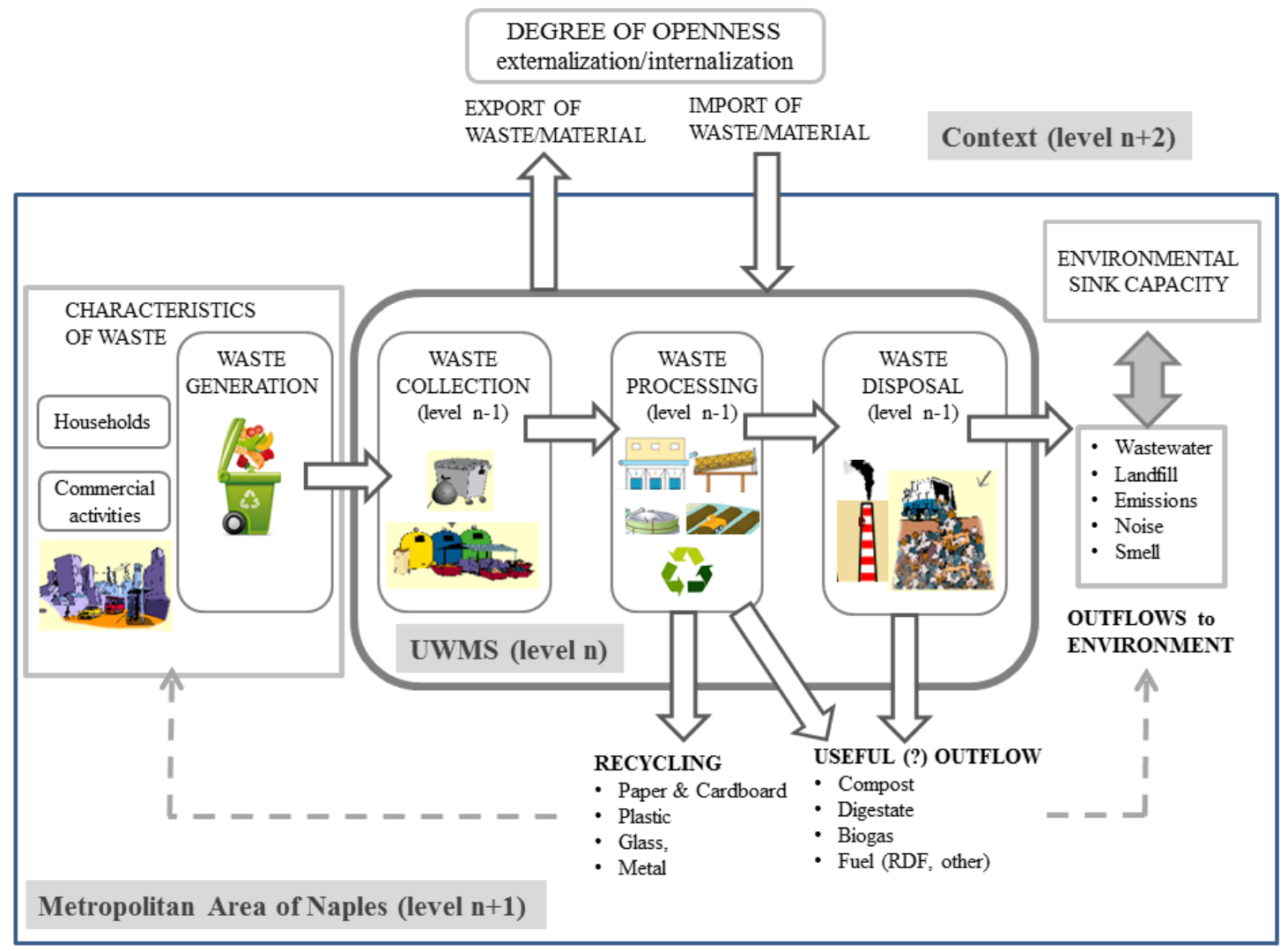

1

2 Figure 3: Conceptual semantic framework to characterize the metabolism of urban waste

3 management systems (UWMS) in relation to their context
5

The external view of the UWMS covers four crucial aspects:

1. The quantity and quality of the waste generated by the urban society that has to be processed by the UWMS;

2. The level of openness of the system as determined by the inflows (import) and outflows (export) of the different forms of waste during the various steps of the waste management process. This information is essential to assess the degree of externalization (or internalization) of environmental problems to (from) other socio-ecological systems;

3. The final quantity and quality of wastes, particles and pollutants (solid, liquid and gaseous) that result from the overall functioning of the UWMS and that are disposed of into the local environment. Together with the given sink capacity of local ecological funds this determines the environmental impact of the UWMS;

4. The effects that the operation of the UWMS has on the socio-economic context. These can be measured in terms of: economic costs (fixed and circulating) of the 
structural elements needed to operate the UWMS; benefits of the recovery and recycling of useful material; costs of exporting waste for processing elsewhere (or gains in the opposite case); employment; well-being of citizens; socio-economic 'side-effects' on other sectors, such as impacts on tourism, health care and so forth.

The inside view focuses on a detailed analysis of the various functional nodes/compartments that make up the UWMS. We distinguish three major steps: waste collection, processing and disposal (see Fig. 3). These steps can be carried out in different ways, and the chosen modalities will determine the identity of the metabolic network: What functional nodes and what topological relations are established over the different flows across the nodes. In turn, the network identity determines the 'processing capacity' demanded from the structural elements operating within the functional nodes.

- Step 1, waste collection takes place at the interface between the UWMS (level n) and the urban context (level $n+1)$. Solid municipal waste may be collected in different ways (door-to-door, street containers, underground containers), separately (e.g., recyclables, organic waste) or mixed (and sorted afterwards);

- Step 2, waste processing concerns the internal activities taking place within the UWMS. Waste processing can be done in different ways using different technologies. The specific processing technologies adopted (structural elements) will imply different degrees of recycling and a different handling of organic waste. Inside the network, solutions adopted for processing depend on the choices made for waste collection (in Step 1), and will affect the possible solutions for final waste disposal (in quality and volume in Step 3). In the step of wasteprocessing it is essential to distinguish between waste flows that: (i) are processed by a successive functional node (remaining in the network at level $n$ ); (ii) are returned to society (recycled; re-used at level $\mathrm{n}+1$ ); and (iii) are exported (as byproducts) outside of the socio-ecological system boundaries (externalization at level $\mathrm{n}+2$ ); (iv) are escaping into the local environment as emissions (percolate, particles, etc., at level n+1) (see Fig. 3).

- Step 3, waste disposal takes place at the interface between the UWMS (level n) and the embedding local ecosystems (level $n+1)$. Virtually any UWMS has a certain share of waste going to landfills and/or incineration plants. However, one should be aware that externalization of waste can also represent an important form of disposal (as is the case for the Metropolitan Area of Naples). 
1 The generic representation of the UWMS shown in Fig. 3 obviously implies ambiguity in

2 the relation between functional nodes and the composing structural elements. The same

3 three steps can be realized with different combinations of functional nodes, and the same

4 functional nodes can be operated with different technologies. For this reason, in the next

5 section, we use a concrete case, the Metropolitan Area of Naples (Italy), to further

6 elaborate and illustrate the proposed framework of analysis.

7

$8 \quad 3.2$ The Neapolitan case

9 In this section we use the case of the Metropolitan Area of Naples to further elaborate and 10 validate the idea of the UWMS as a metabolic network. A top-down characterization of 11 the metabolic pattern of the Neapolitan UWMS is provided in Fig. 4. It shows the functional nodes and their topological relations, as well as a quantification of the flows (in metric tons per year) entering and exiting the individual nodes. A close-up of this characterization of the 'network niche' is illustrated for the node Mechanical Biological Treatment (MBT) in Fig. 5.

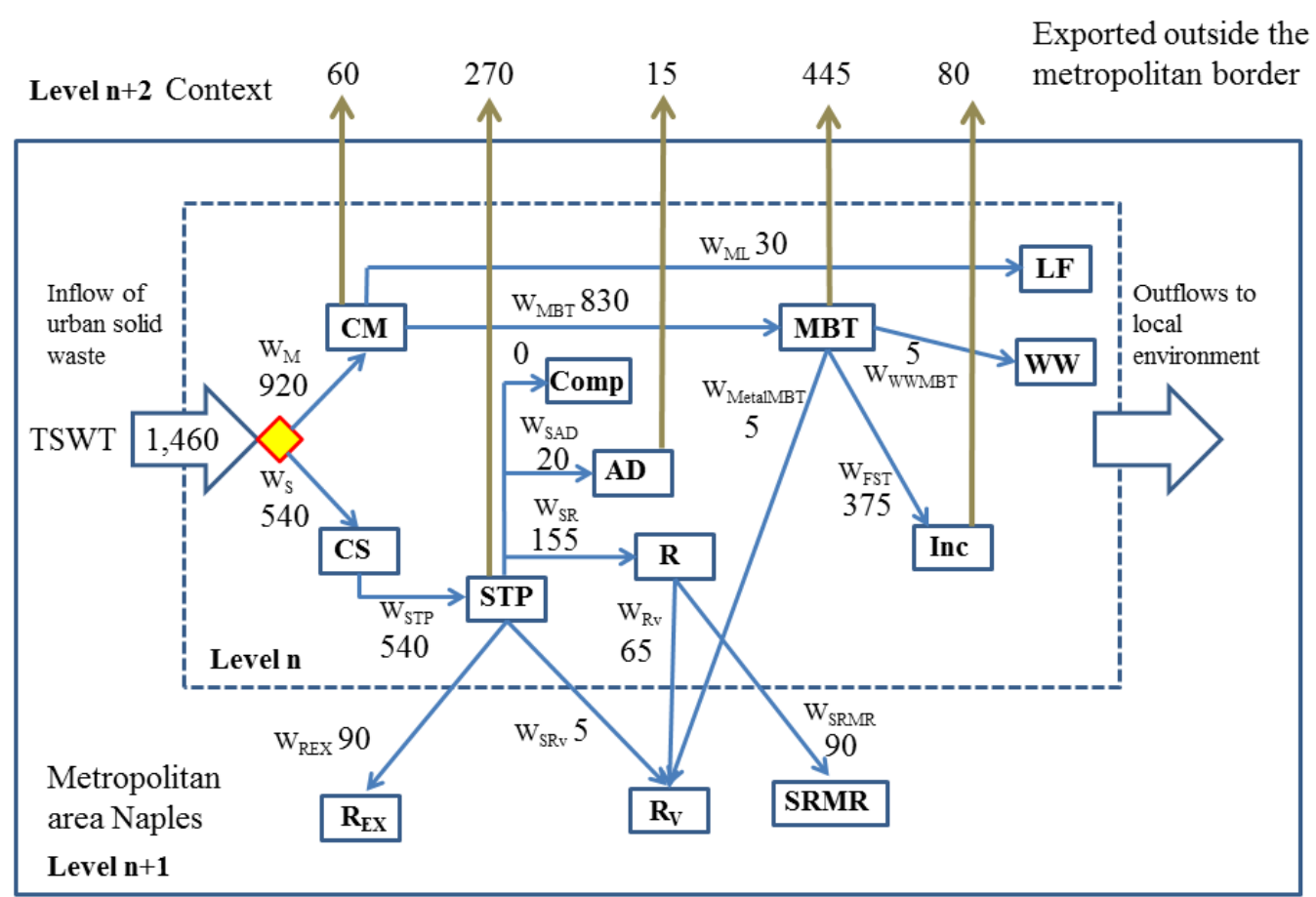


1 Figure 4: The network of functional nodes of the UWMS of the Metropolitan Area of

2 Naples (external view) and quantification of the related waste flows (in $10^{3}$ metric tons per year). Data refer to 2012. Abbreviations are listed in Box 1.

5 BOX 1 Labels identifying nodes and flows in the metabolic network shown in

7 Functional nodes: CM: mixed collection; CS: separated waste collection; MBT: mechanical

Flows: TSWT: Total Municipal Solid Waste Throughput; $W_{M}$ : Mixed Municipal Solid Waste; $W_{M B T}$ : Mixed Municipal Solid Waste sent to Mechanical Biological Treatment; $W_{M L}:$ Mixed Municipal Solid Waste sent to Landfill; $W_{F S T}$ : Dried Fraction coming from MBT sent to Incineration; $W_{W W M B T}$ : Waste Water coming from MBT sent to waste water treatment plants; $W_{\text {MetalMBT: }}$ Recovered metals from MBT; $W_{S}$ : Separated Municipal Solid Waste; $W_{\text {STP: }}$ Separated Municipal Solid Waste sent to Sorting Transfer Platforms; $W_{S A D}$ : Biodegradable Waste from separated collection sent to Anaerobic Digestion; $W_{S R}$ : Dried Separated Municipal Solid Waste sent to Recycling Centers; $W_{R E X}$ : Dried Separated Municipal Solid Waste sent to Recycling Centers outside the MAN; $W_{S R M R}$ : Recycled Material coming from Recycling Centers sent to Secondary Raw Material Recycling; $W_{R v}$ : Processed Separated Waste coming from Recycling Centers sent to Recovery; $W_{S R v}$ : Refuse from Separated Municipal Solid Waste Sorting Platforms sent to Recovery.

$W_{F U T L F}$ : Unstabilized Organic Fraction coming from MBT sent to Lanfill; $W_{M B T w w}$ : Waste Water coming from MBT sent to waste water treatment plants; $W_{F U T S}$ : Stabilized Organic Fraction coming from MBT; $W_{F S T}$ : Dried Fraction coming from MBT sent to Incineration; $W_{F U T}$ : Unstabilized Organic Fraction coming from MBT sent to other treatments; 


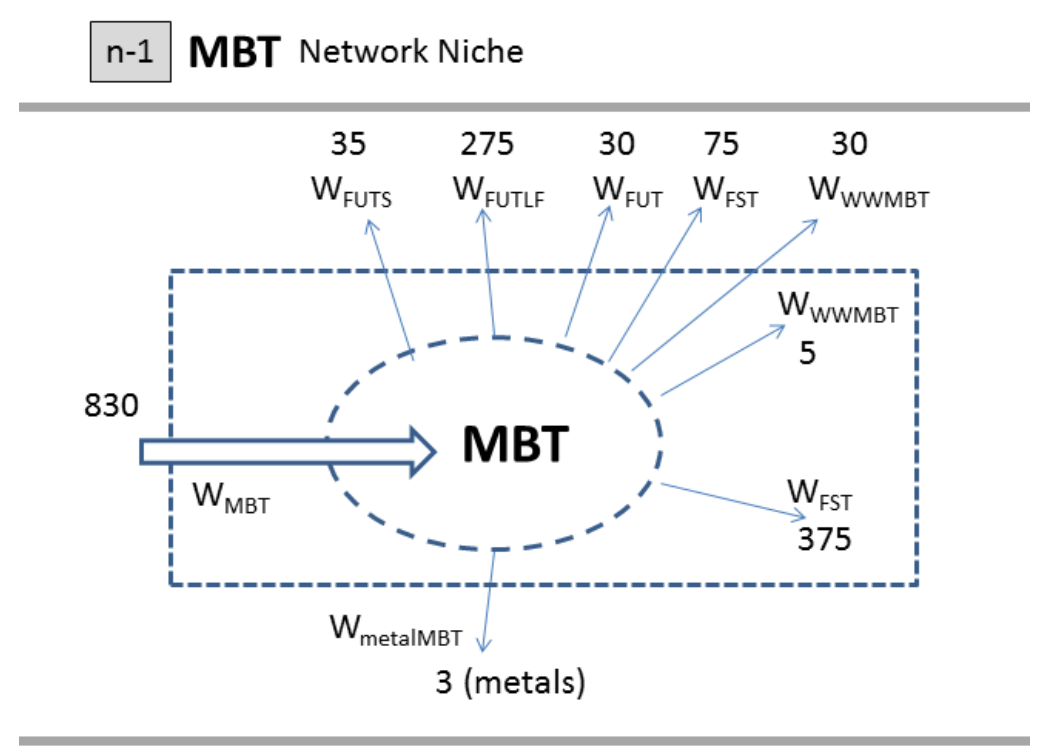

1

2 Figure 5: Quantitative representation of the node Mechanical Biological Treatment 3 (MBT) based on the outside view. Abbreviations are explained in Box 1. Data are in 10 $4 \quad$ metric tons/year and refer to the Metropolitan Area of Naples and the year 2012.

5

6 We can also open up the 'black box' and look at the characteristics of the structural 7 elements that make up the node and determine its properties in terms of: (i) the 8 composition of the material flows; and (ii) the relations between inputs and outputs. An 9 example of a bottom-up representation of the characteristics of the structural elements 10 operating within the node MBT is given in Fig. 6. In the case of Naples, there are three structural elements: (i) 2 MBT plants of type $\alpha$, each with a capacity of $473 \times 10^{3}$ metric tons/year, which have been operating at 59\% of their capacity in 2012; (ii) 1 MBT plant of Type $\beta$, with a capacity of $607 \times 10^{3}$ metric tons/year, which has been operating at $45 \%$ of capacity in 2012. The relation between the actual processed throughput and the processing plant capacity is a service performance indicator recommended by UNEP (2005). Note that the expected relations between the input and outputs of the different typologies of plant in Fig. 6 are expressed as technical coefficients (per thousand metric tons of input). 
n-2 MBT Structural Elements

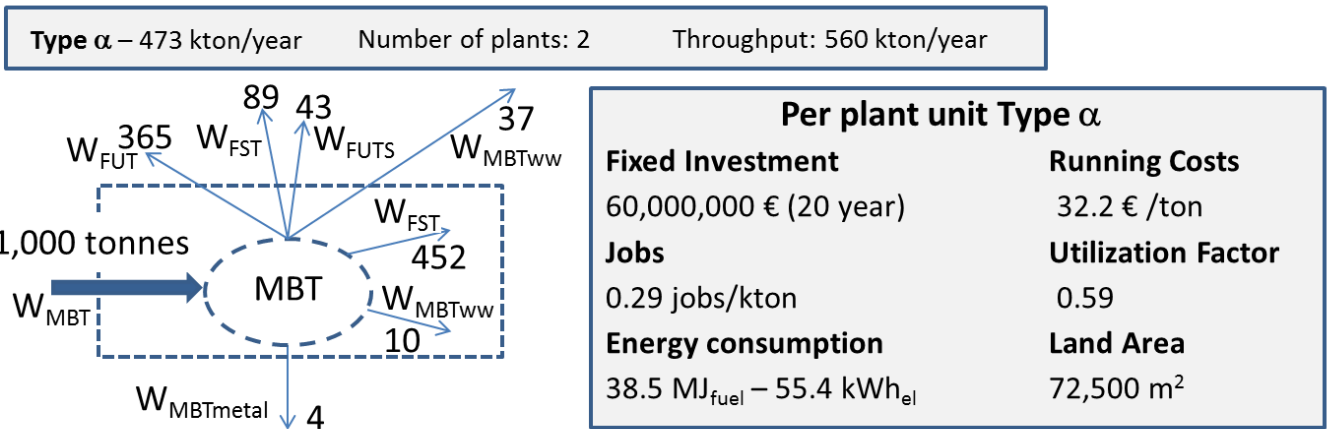

Type $\beta-607$ kton/year Number of plants: $1 \quad$ Throughput: 274 kton/year

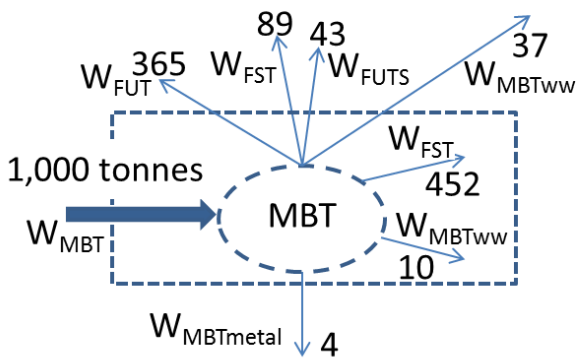

\begin{tabular}{|ll|}
\hline \multicolumn{2}{|c|}{ Per plant unit Type $\beta$} \\
Fixed Investment & Running Costs \\
$65,000,000 €(20$ year $)$ & $29.9 € /$ ton \\
Jobs & Utilization Factor \\
0.37 jobs/kton & 0.45 \\
Energy consumption/ton & Land Area \\
$37.9 \mathrm{MJ}_{\text {fuel }}-66.5 \mathrm{kWh}$ & $110,000 \mathrm{~m}^{2}$ \\
\hline
\end{tabular}

2 Figure 6 Quantitative representation of the node MBT looking at its structural elements

3 and their characteristics (inside view). Flows are reported in metric tons.

4

5 The two views presented in Figs. 5 and 6 are analogous to those presented in Fig. 3. Note

6 that for each of the waste flows reported in Figs. 4, 5 and 6, we can detail the composition

7 by specifying the mix of different fractions (e.g., biodegradable, paper \& cardboard,

8 plastic, glass, metal, other). For instance, in Fig.7 we illustrate the average composition of

9 the collected waste in the Metropolitan Area of Naples. Detailed information about the

10 composition of all the different flows from/to the different nodes is beyond the scope of

11 this paper and will be published elsewhere. 


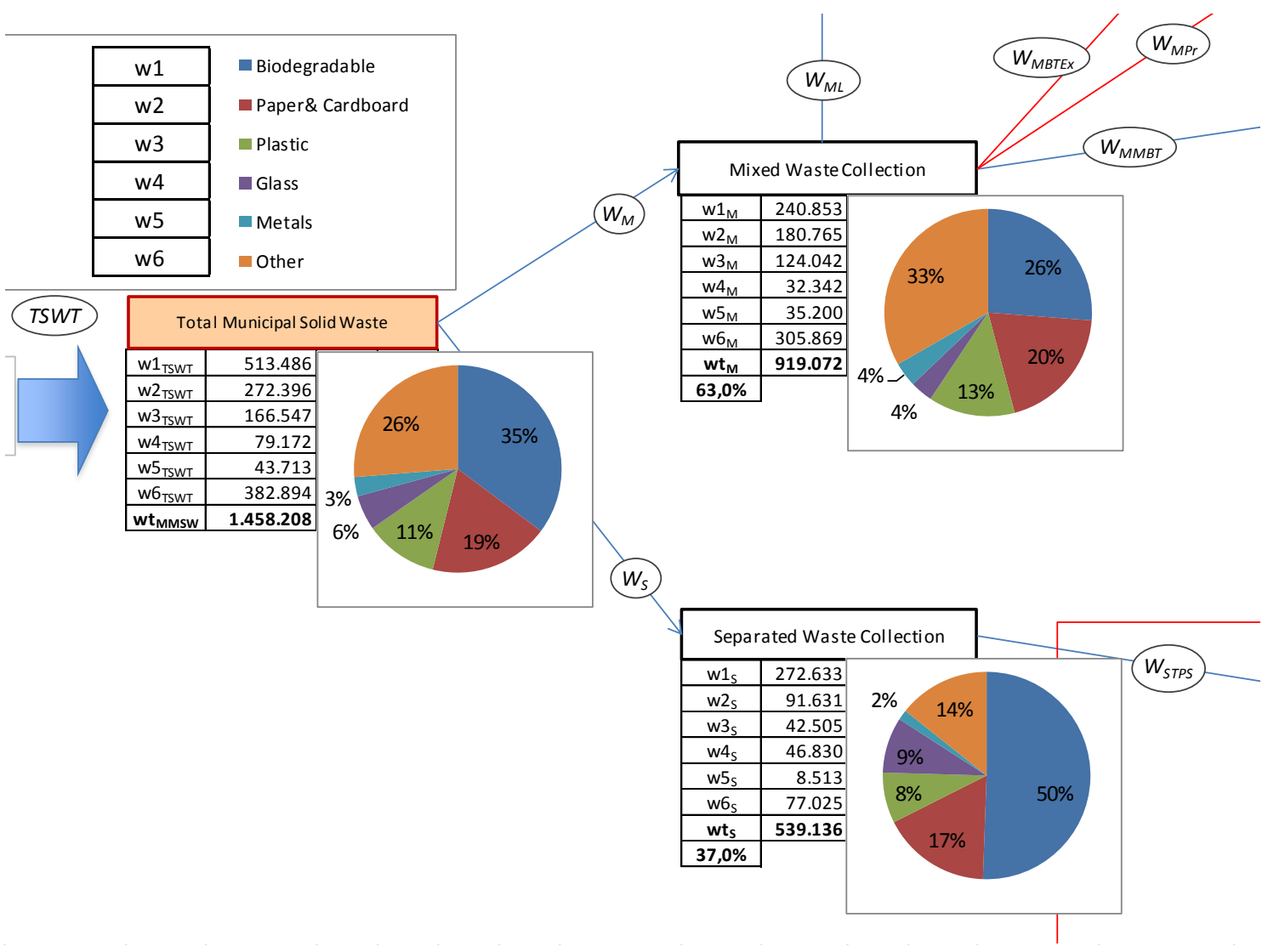

2 Figure 7 Composition of waste flows in the collection stage of the network of the UWMS of the Metropolitan Area of Naples in 2012. Data are in metric tons/year.

4

$5 \quad 3.3$ Indicators characterizing the performance of the UWMS

6

\section{$7 \quad$ 3.3.1 Openness of the network}

8 Starting out from the description of the metabolic network (Fig. 4) we can identify the 9 nodes from which flows are leaving the UWMS into the context. This analysis is 10 important because flows exiting the network signal either an excess of input relative to 11 the capacity of the node in question (saturation of the capacity of lower-level structural 12 elements) or economic convenience (the cost of exporting the flow is lower than that of 13 processing within the network), or both. An example of an analysis of the openness of the 14 system is given in Fig. 8. 


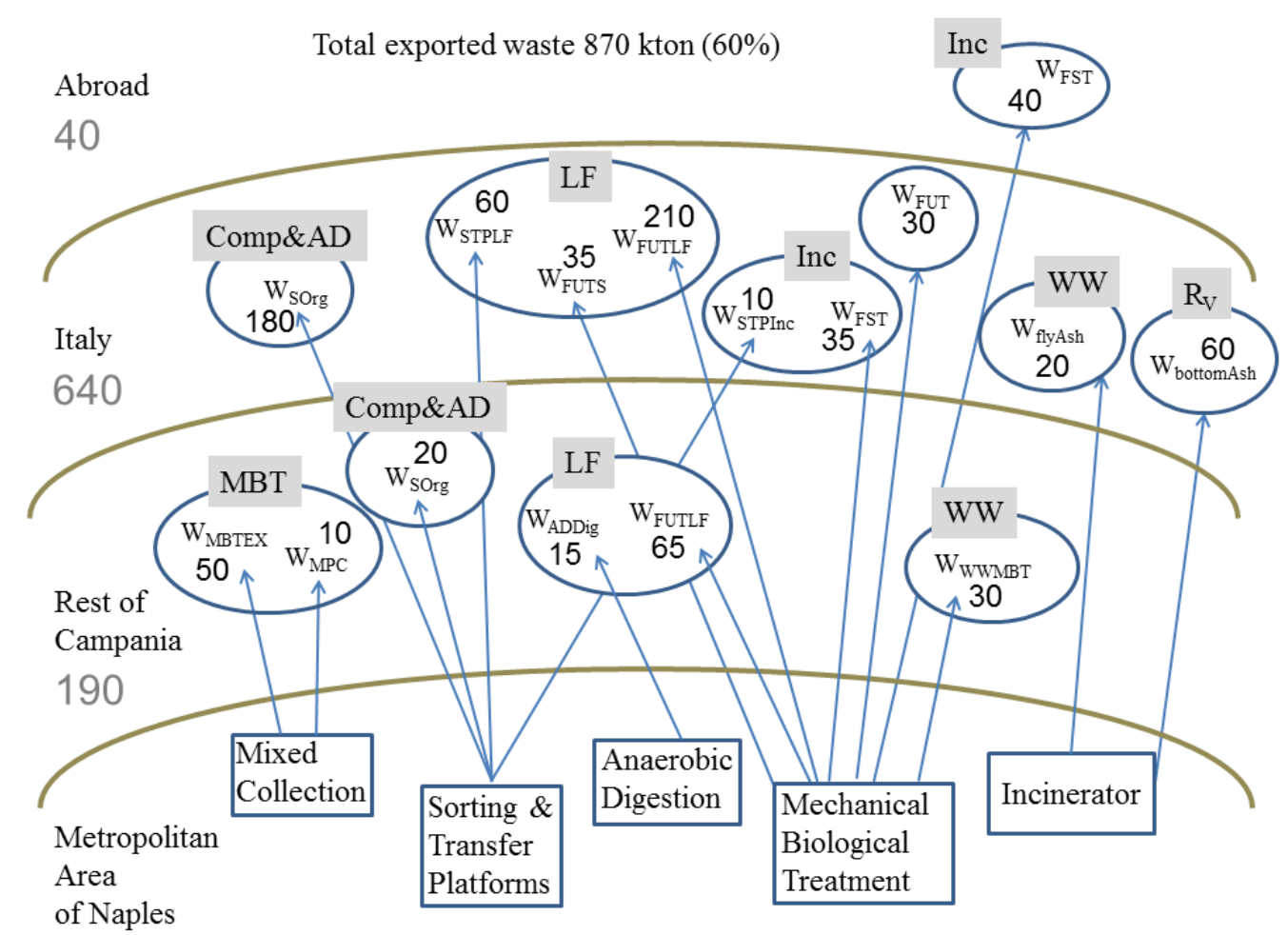

1

2

3 Figure 8: Analysis of the flows released into the context from specific nodes of the UWMS

4 network of the Metropolitan Area of Naples. Data are in $10^{3}$ metric tons/year and refer to

5 the year 2012.

6

7 In Fig. 8, we represent the destination of the flows on the basis of: (i) a spatial criterion 8 (flows are entering a node elsewhere in the region of Campania, in other regions of Italy, 9 or abroad), and (ii) a functional criterion (individuating the type of processing capacity required by the characteristics of the flow). For example, $\mathrm{W}_{\text {FUTLF }}$ (unstabilized organic fraction coming from MBT sent to landfill) requires land-fill capacity, independently of the location of the landfill. It is important to combine these two criteria in the organization of the information as it makes the system of accounting more useful for discussing policies and scenarios at different scales. For instance, administrators of the Region Campania can easily see the connections between the local and the regional network. Also, it can help administrators to estimate trade-offs between increasing the capacity of selected local nodes and exporting in relation to projected changes in population size and/or solid waste throughput (quantity and quality) per person. 
1 The percentage of waste (on the total throughput) that is exported outside of the system is

2 an indicator of the 'degree of openness' of the system. In the year 2012, in the

3 Metropolitan Area of Naples $60 \%$ of the urban waste generated was exported outside of

4 its borders. Only $13 \%$ of the exported flow was actually treated within the region

5 (Campania), the remaining 47\% was exported to other Italian regions or abroad. These

6 figures stand in stark contrast to the ambitious goal of regional self-sufficiency in waste

7 treatment and disposal laid down in the 2007 Regional Plan for Waste Management of

8 the Campania Region $\left(\mathrm{PRGRC}^{6}\right.$ ) as well as in the Italian legislative decree 152/2006.

9

\subsubsection{Socio-economic impact of the network}

Combining the information on (i) operating costs and labor requirements for the structural elements within the individual functional nodes (see Fig. 6); (ii) recycling of material and production of useful outputs for society; and (iii) export of wastes (a cost for the local administration of the Neapolitan UWMS), we can estimate the monetary flows associated with the operation of the UWMS as well as the number of jobs created, as illustrated in Fig. 9. In the case of Naples, we also have to include the maintenance and safeguarding of 5.7 million tons of 'eco-balle', a temporary storage of waste excess generated in the crisis period of 2001-2009. In this way, we can carry out a check on the viability of processes under human control, both in relation to technical viability (compatibility of the technical characteristics of the elements of the metabolic network) and economic viability (the resulting monetary flows). Note that the data provided in Fig. 9 are rough estimates and only serve to illustrate the approach.

${ }^{6}$ PIANO REGIONALE per la GESTIONE dei RIFIUTI URBANI della REGIONE CAMPANIA - legge regionale $4 / 2007$. 


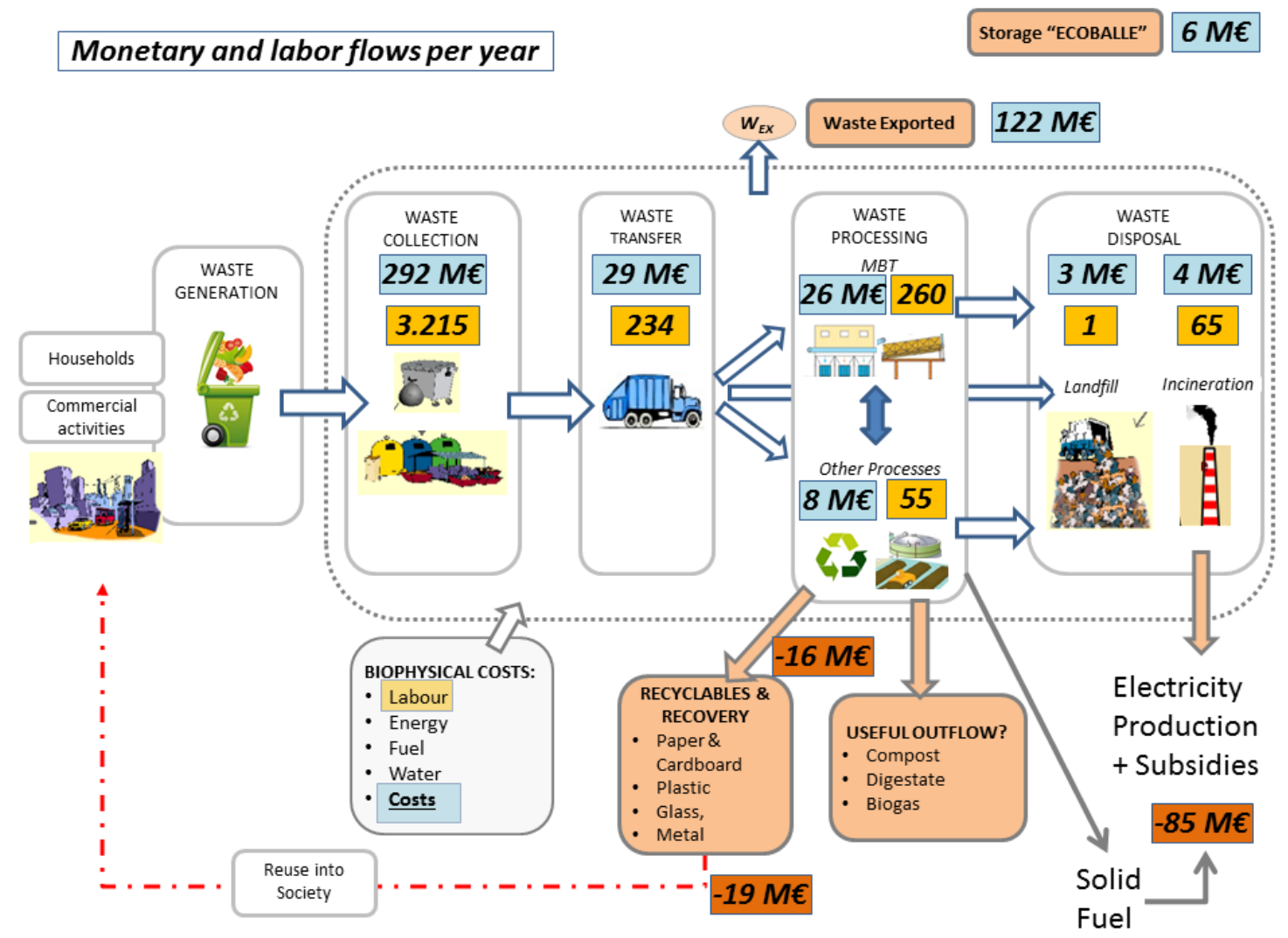

Figure 9: Preliminary assessment of the monetary flows (at 2012 market prices) and jobs created (in units of full-time positions) for the UWMS of the Metropolitan Area of Naples based on metabolic network analysis.

Fig. 9 shows that in the Metropolitan Area of Naples, waste collection accounts for the larger part of the economic costs of the UWMS (292 M€/year). However, an important part of this monetary flow remains in the city in form of wages for local workers and revenues for local operators. Waste export also represents a significant economic burden for the local administration (122 M€/year). The large flow of export is a result of shortage of processing capacity at the level of structural elements in key nodes. Using the proposed approach, one can analyze the processing capacity and relative economic investments in the different nodes for generating alternative network configurations (by changing characteristics of functional nodes, e.g. through the adoption of new technologies and/or changing connections over nodes) to achieve a planned reduction of waste export.

7 The monetary values illustrated in Fig. 9 can be interpreted as costs or benefits depending 8 on the perspective adopted. For instance, labor represents a monetary cost for the local 
administration but benefit (wages) for the community. The same reasoning applies to other monetary flows between interacting economic agents in the UWMS. The flows indicated in the bottom part of Fig. 9, such as recycled material or useful output like biogas, fuels or compost, provide an economic return for the local administration, although in the case of Naples the revenue is relatively small compared to the costs: In 2012, the local administration received around $16 \mathrm{M} €$ for delivering recycled materials to private companies. In this case, the $16 \mathrm{M} €$ is a benefit for the local administration, but a cost for the companies. The added value generated by the private companies processing the recycled material has been evaluated at $19 \mathrm{M} €$.

A similar situation is found for the operation of the incinerator, the benefits of which are equally shared between the Campania Region (regional public administration) and the private operator of the plant. The estimated value of $85 \mathrm{M} €$ reported in Figure 9 includes the sale of the net quantity of electricity produced by the incineration plant and subsidies received from the central government. The monetary flow coming from sale of electricity is around $25 \mathrm{M} €$ and has been calculated on the basis of the average cost of $1 \mathrm{kWh}$ in Italy in 2012 applied to the electricity generated with the fuels. The remainder consists of public subsidies (approximately $60 \mathrm{M} €$, estimated from data published by D’Alisa et al., 2010).

The ambiguity in the assessment of economic costs and benefits for the UWMS shows the importance of discussing pre-analytical decisions with those using the results of the quantitative analysis for decision-making. Costs and benefits for whom? When it comes to the criterion 'desirability' it is important to recognize that different social actors do adopt different, but equally legitimate definitions of economic costs and benefits. This means that the choice of an integrated set of indicators of socio-economic performance should always include a participatory phase in which the pre-analytical choices of storytelling (how to reflect the monetary flows in a system of indicators) are checked with those that will use the results of the model.

\subsubsection{Environmental impact of the network}

To assess and monitor the environmental impact of the emissions generated by the UWMS, we must study the level of disturbance that the metabolic pattern of the UWMS generates on the metabolic pattern of the embedding ecological system. A discussion of 
1 how to use a multi-scale characterization of the metabolic pattern of socio-ecological systems to develop indicators of environmental impact organized in an environmental impact matrix has been described elsewhere (Giampietro and Lomas, 2014). An overview of the proposed approach, applied to the Neapolitan UWMS, is illustrated in Fig. 10. Briefly, we have to organize our information as follows:

1. Individuate and categorize the nodes generating significant emissions into the environment, and represent them in quantitative and qualitative terms both in space and in time;

2. Individuate and categorize the local ecological systems in the context and, for each of them, identify and describe the attributes to define threshold values of critical environmental loading;

3. Select a mix of indicators of Environmental Impact (EI) capable of characterizing the level of stress caused by the selected emissions. This integrated set of EI indicators must be able to observe processes taking place at different scales. It is important that indicators of environmental impact are specific to the characteristics of local ecological funds. This implies the need of using spatially geo-referenced data that can be used to both characterize and monitor in time the environmental performance of the UWMS.

Participatory processes are useful to check the quality of the choices made with regard to nodes, indicators and ecosystem funds, and of the relative system of monitoring (e.g., location and number of control units, definition of emission limits). 


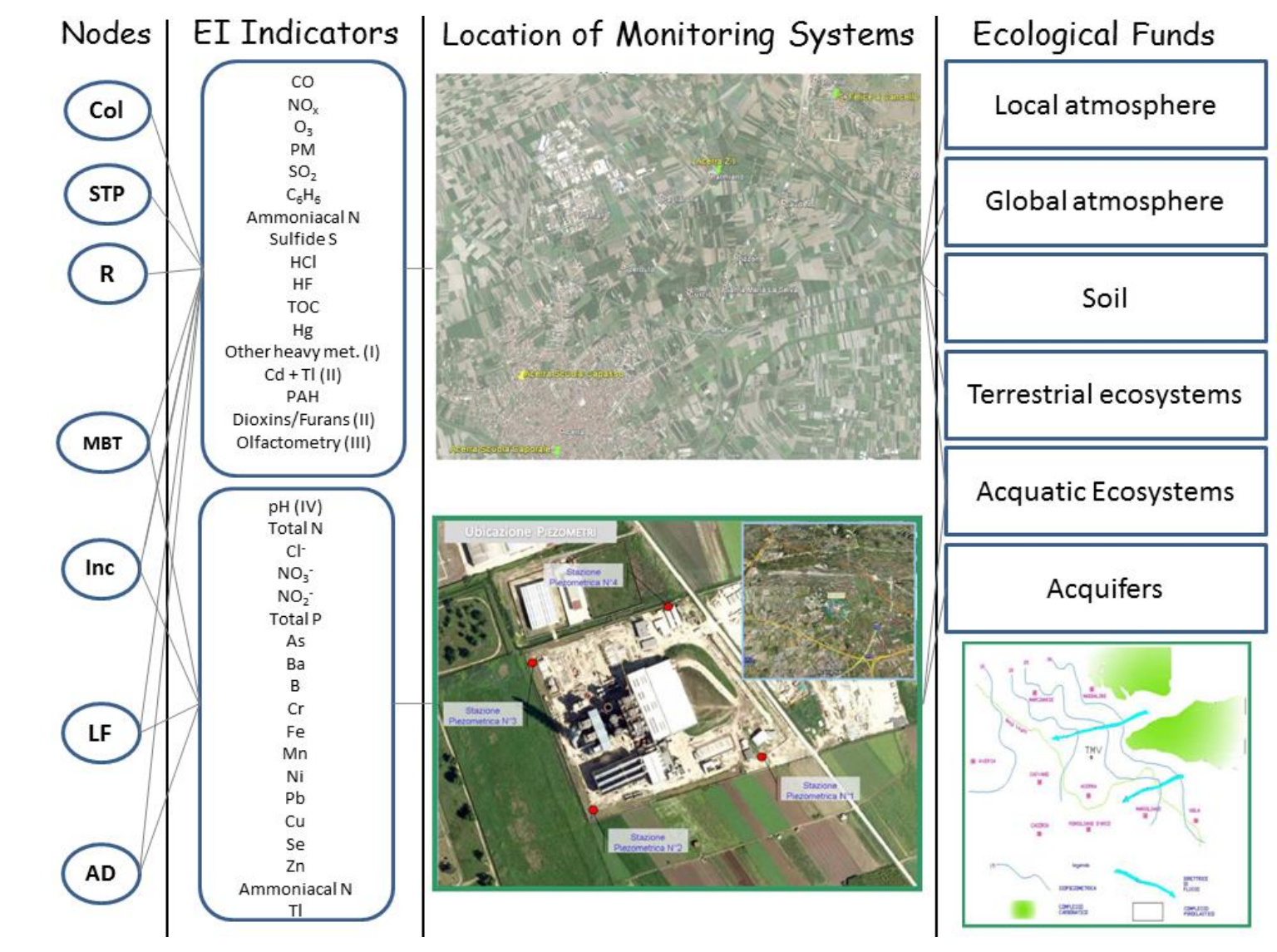

2 Figure 10: Example of environmental impact indicators for the case of Naples: Air and

3 water emissions from specific nodes of the network in relation to relevant ecological

4 funds in the context. The corresponding legislative framework consists of: European directive

5 2008/50/EC; Italian legislative decree 152/2006; “Ordinanza commissariale 258/2003” specific

6 for MBT plants; "Autorizzazione Integrata Ambientale" (AIA) from ARPAC specific for the

7 Acerra incinerator; the AIA and "Ordinanza commissariale" 289/2009 specific for the Terzigno

8 landfill. Notes and abbreviations: (I) Other heavy metals: $\mathrm{Sb}, \mathrm{As}, \mathrm{Pb}, \mathrm{Cr}, \mathrm{Co}, \mathrm{Cu}, \mathrm{Mn}, \mathrm{V}, \mathrm{Ni}, \mathrm{Zn}$,

9 Sn; PAH: Poly-Aromatic Hydrocarbons; PM: Particulate Matter; TOC: Total Organic Carbon.

In the example shown in Fig. 10, we have: (i) in the far left column: the nodes whose activity could potentially generate relevant emissions (in this case waste collection is treated as a unique system, including both $\mathrm{CS}$ and $\mathrm{CM}$ ); (ii) in the second column: the indicators of environmental impact (upper set: air emission; lower set: water emission); (iii) in the third column: the location of the nodes generating emissions and the relative monitoring systems (the example shows the incinerator of Acerra in the Metropolitan Area of Naples and the location of the air-quality control units in the surrounding area [upper photo], and the positions of the upline and downline observation wells [lower photo]); (iv) the far right column: typologies of vulnerable ecosystem funds (the example 
1 shows groundwater flows in the Acerra microregion affected by local effluents from the

2 incinerator). The most controversial facilities, that is, the incinerator, the landfill and the

3 MBT plants, installed and erected despite the aversion of the local population, are

4 subordinated to specific higher standards, with lower concentrations of the effluents

5 allowed. The environmental performance of the above-mentioned plants has generally

6 been within the prescribed limits, with the exception of the landfill in Terzigno, which

7 has been accused of exceedances in water emissions for metals such as manganese and

$8 \quad$ zinc as well as other species ${ }^{7}$.

\subsubsection{Integrating indicators of UWMS performance}

The holistic framework illustrated in this paper is useful to bridge information referring to different levels of analysis (local and meso scale) and different data sources (bottom-up information about the characteristics and use of technologies versus top-down statistics describing the functional compartments). Starting from a general semantic characterization of the UWMS (Fig. 3), we arrive at a representation of the metabolic network (Fig. 4) based on the identification of functional nodes and their topological relations inside the system (level n-1) (Fig. 5) and with its context (levels $n+1$ and $n+2$ ) (Fig. 8). Flows exiting or entering the network (exported or imported flows) are accounted for because of their economic relevance and externalization of impact (Fig. 9). For example, the analysis of the nature and source of exported waste flows for the Neapolitan UWMS (Fig. 8) clearly shows the typologies of technological capacity that are externalized, as well as the implications of the choice of system boundary for the analysis (e.g., the Metropolitan Area of Naples versus the whole region of Campania).

The proposed framework also makes it possible to interface the analysis of the performance of the UWMS with an analysis of environmental impact, that is, the feasibility of the operation of the UWMS in relation to the carrying capacity of the embedding ecosystems and the related regulations imposed by the local, regional and central governments (Fig. 10). For example, the massive export of waste material (for composting, for land-fills, including both the fly and the bottom ash from the incinerator) outside of the Metropolitan Area of Naples has been an emergency strategy to provide for

\footnotetext{
${ }^{7}$ Report accusing: http://www.comune.boscotrecase.na.it/files/Microsoft\%20Word\%20\%20Relazione tecnica finale.pdf, report denying: http://www.altrestorie.org/Allegato\%207.pdf.
} 
1 the severe lacking of local processing and disposal capacity. Within our framework, we

2 propose to track the flows of emissions from each node into the ecological funds likely to

3 be affected. Linking emissions and other environmental problems to specific network

4 nodes not only makes it possible to study the environmental impacts of proposed

5 scenarios (simulating different network configurations), but also to carry out a transparent

6 discussion about the monitoring of environmental impacts. The proposed framework

7 facilitates the use of geographic information systems to localize and visualize emissions

8 (as illustrated in Figure 10), which is extremely useful for a transparent communication

9 with the public.

10 As shown by our preliminary findings in the Naples case study, the proposed holistic framework for the integrated assessment of the performance of UWMS can generate a set of relevant indicators reflecting the concerns and goals of different stakeholders. Other indicators, such as proposed by Armijo (2011) and UNEP (2005), can also be accommodated within the framework.

For each typology of stakeholders interviewed in Naples, we found different storytelling about the performance of the UWMS. The public administration expressed its concern about the high economic costs (including labor costs) of the operation of the waste management system. In contrast, the creation of jobs was considered positive by the unemployed councils. Citizens, NGOs and activists were basically concerned with the (lack of) transparency and effectiveness of the monitoring of emissions from the plants and the resulting environmental harm. This diversity of storytelling, associated to different goals and concerns, can be handled by generating a series of dashboards as illustrated in Fig. 11. Note that the current local environmental impact reported in Fig. 11 is relatively low considering the high population density in the area (2600 inhabitants $/ \mathrm{km}^{2}$ ). As mentioned earlier, this is due to the fact that almost $60 \%$ of waste produced is being exported. This massive externalization of environmental impacts implies high economic costs for the operation of the UWMS. 


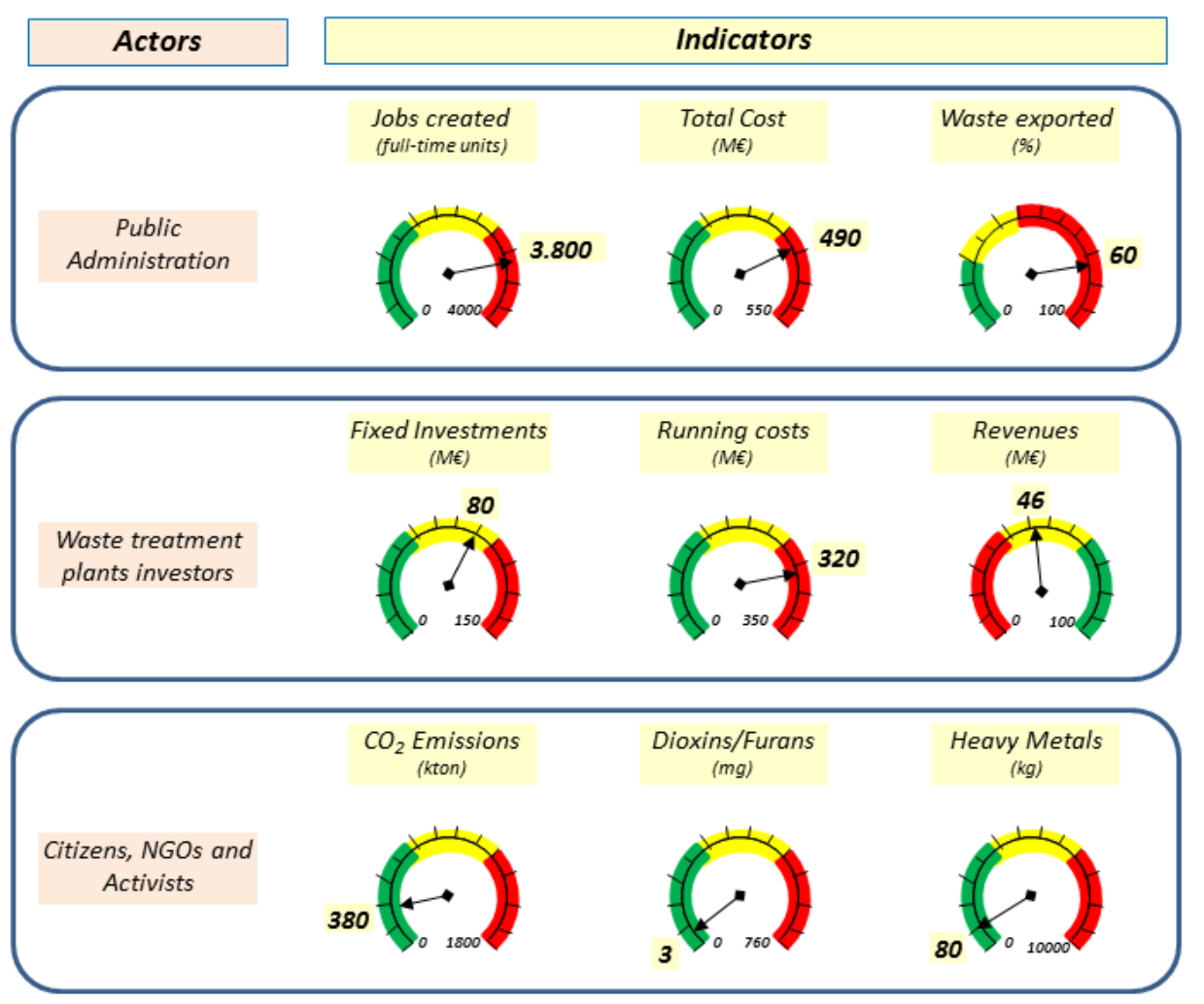

1

2 Figure 11: Relevant indicators of UWMS performance for different story-telling by

3 stakeholders in the Metropolitan Area of Naples. Indicators refer to the operation of the

4 entire UWMS and represent the sum over the various network nodes. The color code red,

$5 y$ yellow and green corresponds to bad, average and good performance respectively. Data

6 presented are preliminary and only serve to illustrate the proposed approach.

7

\section{4. CONCLUSIONS}

9 The approach presented in this paper is innovative in that it is based on theoretical concepts from complexity theory (metabolic network, flow-fund model, holons and holarchy). It is the first attempt to apply the MuSIASEM accounting framework to the

12 development of a decision support tool for the integrated assessment of the performances

13 of UWMS. We believe that the proposed framework has the potential to integrate

14 different type of indicators -social, economic; environmental-across different scales and dimensions of analysis. 
1 Evaluation of scenarios. One important feature of the proposed approach is the evaluation

2 of proposed scenarios. The quantitative relations between the outside and inside view of network nodes (functional element of the network-network niche versus structural elements of the node-technical coefficients) are not deterministic. Therefore, it has to be decided, node by node, what can be done to obtain congruence in the simulation: exporting (when capacity to process the new input flow is insufficient) or increasing capacity by adding new/changing structural elements. As soon as we decide what to do with a node, this choice will be reflected in the flows reaching successive nodes, which, in turn, will have to be adjusted to the new input flows in a similar way. Rather than generating simulations of deterministic dynamic trajectories, this approach explores the option space, providing for the proposed scenarios an analysis of the pros and cons in relation to the chosen indicators. Clearly, this exploration requires a continuous input from the end-users with regard to: (i) relevant hypotheses of network identities; (ii) relevant indicators for characterizing the performance of the UWMS; (iii) solutions for dealing with lack of congruence in individual nodes.

Semantically open framework. Different relevant storytelling demands correspondingly different integrated characterizations. Hence, to be useful in different geographic and cultural contexts, the holistic framework for the integrated assessment of UWMS must be able to accommodate performance indicators tailored to specific local situations. The use of performance indicators of the type 'one size fits all' simply does not work. The approach proposed in this paper can be considered a meta-tool for carrying out a quantitative characterization of the metabolic pattern of complex waste management systems. It is essentially a semantically open framework that can accommodate indicators related to the environmental, legal, political, economic, technical, public health, and socio-cultural spheres, and therefore allows an informed discussion among the various stakeholders over the performance of UWMS. As argued by Scholz and Steiner (2015), the construction of proper meta-levels of reflection, validation, and integration is expected to play an important role in the future development of sciences.

Quantitative story-telling. The holistic approach to integrated assessment presented in this paper makes it possible to improve the quality of the process of production and use of quantitative information for UWMS-related policies. It can be used in combination with participatory processes to identify the different perceptions (story-telling) of the social actors involved and characterize the advantages and disadvantages of different types of 
1 UWMS in a multi-criteria setting. This new way of using quantitative analysis, that we call quantitative story-telling, implies a new level of collaboration between the producers and users of quantitative information. The two sides have to work together from the outset in order to guarantee the quality of the process, integrating different types of available information in order to obtain the big picture of the problems at stake.

Transparency. The proposed representation of the functioning of the UWMS and the characterization of its performance reflecting the different interests of different social actors increases the transparency of the process of evaluation and decision making. In the case of Naples, this transparency is badly needed to restore the credibility and legitimacy of decision makers.

Shortcomings. Application of the proposed holistic framework for integrated assessment of UWMS performance to the Metropolitan Area of Naples shows that the proposed approach requires large amounts of data that have to be retrieved from multiple and variegated sources. Given the peculiarity of the Neapolitan UMWS (scandals and waste crisis in the recent past) it has been difficult to obtain reliable data and information on the numerous network nodes. To obtain reliable results it is necessary to continuously integrate statistical data (which are not necessarily easy to obtain) with the expertise of practitioners (for double checking the credibility of the data with expert estimations). Practitioners and administrators are busy people and it is often difficult to engage them in a meticulous and time-consuming cross-check of information. Moreover, it is not unusual to find that experts in different departments/institutions provide widely different estimates of the technical coefficients for the same plant/facility. This is due to the adoption of different storytelling including or excluding important attributes. Clearly we hope that over time participatory research methods will become more commonplace and that once the end-users recognize that they can benefit from the results, these difficulties can be overcome.

\section{Acknowledgement}

This research has been developed within the project MARSS-Material Advanced Recovery Sustainable Systems (contract LIFE11 ENV/DE/343) funded under the EU LIFE+ Programme. We are indebted to Michele Rampone (Campania Region) for participating in the DELPHI process, to Maddalena Ripa and Valentina Vacca 
1 (University Parthenope of Naples) for the precious source of data, to ARPAC for the

2 Acerra area's pictures, as well as to Ignasi Puig for his valuable comments on an earlier

3 draft of this paper, and finally for the useful comments and suggestions of the reviewers.

\section{REFERENCES}

6 Ahl, V. and Allen T.F.H. (1996). Hierarchy Theory. New York: Columbia University $7 \quad$ Press

8 Allen, T.F.H. and Starr, T. (1982). Hierarchy: Perspectives for Ecological Complexity. 9 Chicago: University of Chicago Press.

Armijo, C., Puma, A. and Ojeda, S. (2011). A set of indicators for waste management programs. Paper presented at the $2^{\text {nd }}$ International Conference on Environmental Engineering and Applications. IPCBEE, vol. 17, pp. 144-148. IACSIT Press, Singapore.

Bhuiyan, S. H. (2010). A crisis in governance: Urban solid waste management in Bangladesh. Habitat International, 34 (1): 125-133.

Chang, N.B., Pires, A. and Martinho, G. (2011). Empowering systems analysis for solid waste management: challenges, trends and perspectives. Critical Reviews in Environmental Science and Technology 41 (16), 1449-1530.

Contreras, F., Hanaki, K., Aramaki, T. and Connors, S. (2008). Application of analytical hierarchy process to analyze stakeholders' preferences for municipal solid waste management plans, Boston, USA. Resources, Conservation and Recycling, 52(7), 979-91.

D’Alisa, G., Burgalassi, D., Healy, H. and Walter, M. (2010). Conflict in Campania: Waste emergency or crisis of democracy. Ecological Economics 70 (2): 239-49.

D’Alisa, G., Di Nola, M.F. and Giampietro, M. (2012). A multi-scale analysis of urban waste metabolism: density of waste disposed in Campania. Journal of Cleaner Production 35, 59-70.

Fath, B.D. and Patten, B.C. (1999). Review of the foundations of network environ analysis. Ecosystems 2: 167-179. 
1 Fath, B.D., Scharler, U.M., Ulanowicz, R.E. and Hannon, B. (2007). Ecological network analysis: network construction. Ecological Modelling 208: 49-55.

Georgescu-Roegen, N. (1971). The Entropy Law and the Economic Process. Harvard University Press, Cambridge, MA.

Giampietro, M. and Lomas, P.L. (2014). The interface between societal and ecosystem metabolism. In: Giampietro, M., Aspinall, R.J., Ramos-Martin, J. and Bukkens, S.G.F. (Eds.), Resource Accounting for Sustainability Assessment: The nexus between energy, food, water and land use, Routledge, Abingdon (UK), pp. 33-48.

Giampietro, M., Mayumi, K. and Munda, G. (2006). Integrated assessment and energy analysis: Quality assurance in multi-criteria analysis of sustainability. Energy 31(1): 59-86.

Giampietro, M., Mayumi, K. and Sorman, A.H. (2012). The Metabolic Pattern of Societies: Where economists fall short. Routledge, Abingdon (UK).

Giampietro, M., Mayumi, K. and Sorman A.H. (2013). Energy Analysis for a Sustainable Future: Multi-Scale Integrated Analysis of Societal and Ecosystem Metabolism. Routledge, Abingdon (UK).

Giampietro, M., Aspinall, R.J., Ramos-Martin, J. and Bukkens, S.G.F. (Eds.) (2014). Resource Accounting for Sustainability Assessment: The nexus between energy, food, water and land use. Routledge, Abingdon (UK).

Guerrero, L. A., Maas, G. and Hogland, W. (2013). Solid waste management challenges for cities in developing countries. Waste Management 33(1), 220-32. doi:10.1016/j.wasman.2012.09.008

Hannon, B. (1973). The structure of ecosystems. Journal of Theoretical Biology 41: 53546.

Hannon, B. (1985). Ecosystem flow analysis. Canadian Journal of Fisheries and Aquatic Sciences 213: 97-118.

Hung, M.-L., Ma, H., \& Yang, W.-F. (2007). A novel sustainable decision making model for municipal solid waste management. Waste Management, 27(2), 209-19.

Kijak, R. and Moy, D. (2004). A Decision Support Framework for Sustainable Waste Management. Journal of Industrial Ecology 8 (3): 33-50. 
1 Koestler, A. (1968). The Ghost in the Machine. MacMillan, New York.

2 Koestler, A. (1978). Janus: A summing up. Hutchinson, London.

3 Lindeman, R.L. (1942). The trophic-dynamic aspect of ecology. Ecology 23 (4): 399$4 \quad 418$

5

6

7

Margalef, R. (1968). Perspectives in Ecological Theory. Chicago: University of Chicago Press.

Marshall, R.E. and Farahbakhsh, K. (2013). Systems approaches to integrated solid waste management in developing countries. Waste Management 33: 988-1003.

Morrissey, A.J. and J. Browne, J. (2004). Waste management models and their application to sustainable waste management. Waste Management 24: 297-308.

Odum, E.P. (1959). Fundamentals of Ecology (first edition). Saunders, Philadelphia.

Odum, E.P. (1969). The strategy of ecosystem development. Science 164: 262-270.

Odum, H.T. (1971). Environment, Power and Society. Wiley-Interscience, New York.

Odum, H.T. (1983). Systems Ecology. John Wiley, New York.

Odum, H.T. (1996) Environmental Accounting: Emergy and Environmental Decision Making, John Wiley, New York, NY

Patten, B.C. and Auble, G.T. (1981). System theory of the ecological niche. The American Naturalist 117 (6): 893-922.

Rigamonti, L., Sterpi, I. and Grosso, M. (2016). Integrated municipal waste management systems: An indicator to assess their environmental and economic sustainability. Ecological Indicators 60: 1-7.

Rosen, R. (1958). A relational theory of biological systems. Bulletin of Mathematical Biophysics 20: 245-260.

Rosen, R. (1959). A relational theory of biological systems II. Bulletin of Mathematical Biophysics 21: 109-128.

Santibañez-Aguilar, J.E., Ponce-Ortega, J.M., González-Campos, J.B., Serna-González, M. and El-Halwagi, M.M. (2013). Optimal planning for the sustainable utilization of municipal solid waste. Waste Management 33 (12): 2607-22. 
1 Scholz, R.W. and Steiner, G. (2015). Transdisciplinarity at the crossroads. Sustainability $2 \quad$ Science 10: 521-26.

3 Tansley, A.G. (1935). The use and abuse of vegetational concepts and terms. Ecology 16: $4 \quad 284-307$.

5 Thorneloe, S.A., Weitz, K. and Jambeck J. (2007). Application of the US decision 6 support tool for materials and waste management. Waste Management 27: 1006-20.

7 Ulanowicz, R.E. (1986). Growth and Development: Ecosystem Phenomenology. 8 Springer-Verlag, New York.

9 Ulanowicz, R.E. (1997). Ecology, The Ascendent Perspective. Columbia University 10 Press, New York.

11 United Nations, Department of Economic and Social Affairs (UN) (2014). World 12

UNEP (2005). Integrated Waste Management Scoreboard: A Tool to Measure Performance in Municipal Solid Waste Management. United Nations Environment Program Nairobi. Available on line: http://www.unep.or.jp/ietc/Publications/spc/IWM_scoreboard-binder.pdf. Zaman, A.U. (2014). Identification of key assessment indicators of the zero waste management systems. Ecological Indicators 36: 682-93. 